\title{
Exploring the Charm Factors of Microfilm Creation "Living with Medicine and Mercy"
}

\author{
Xiao-Jing Yu \\ Xiamen Academy of Arts and Design, Fuzhou University, Xiamen, Fujian, PR China \\ Corresponding Author: sisishe@163.com
}

\begin{abstract}
Microfilms are highly interactive, open and entertaining, and can enhance the interest and enthusiasm of learning film photography. Microfilm has an open communication platform that can be played on a variety of mobile terminals such as the Internet, mobile phones, and mobile TVs for urban public transportation. It is interactive and participatory. Therefore, in order to discover the charm factors of microfilms which can attract the audiences, and at the same time, taking the microfilm creation "Living with Medicine and Mercy" as an example, explore and compare the charm factors to drive people to watch this microfilm. This research used the Evaluation Grid Method theory from Preference-Based Design, and interviewed six highly involved people in microfilm to proceed related research. The attractiveness factors consisted of originality factors, abstract attractiveness factors and concrete attractiveness factors can be obtained by the Evaluation Grid Method. Among them, the microfilm real story, camera movements, and the emotional aesthetic communication are most recognized by the interviewees. The attractiveness factors can provide effective references for a microfilm creation.
\end{abstract}

Keywords: Evaluation Grid Method, Microfilm, Attractive factors

\section{Introduction}

With the influence of mass communication, the population of watching movies is gradually increasing, and the film media communication has an influence on the values of the public. Especially in these box office movies, the environment in which the characters are located and the ideas that motivate the audience are even used. Appliances, clothing and location are often the focus of fashion.

This study uses the evaluation construction method of fascinating engineering, in-depth interviews with high-investigators of movies, and finds the charm factor of film products.In order to improve the service quality of film and television products, promoters must understand the needs of tourists for film and television products and clarify the correlation between charm attributes and quality attributes. Therefore, this study explores the quality factors of viewers in the film and television industry through attractive engineering.

\section{A. Cultural products}

Cultural products (goods and services) cover art, aesthetics, symbolism and spiritual values. Cultural products are characterized by a system of value proliferation that is not replicable (Throsby, 2001). The film industry is regarded as one of the world's high economic output industries and is regarded as the locomotive of the cultural and creative industry. Film and television text consumption is an indispensable part of many modern people's lives, and its impact and consumption levels can span age, gender, race and national boundaries. Successful video texts, in addition to reflecting text, express experience habits and values. Through watching the experience, it will become the collective memory of that era. The collective memory and idol recognition not only promote culture and creativity to the whole world, but with the industrial effects and economic output value of the text, I am afraid that it is more competitive than the general industry. (Lin Fumei, 2012)

In addition, the film industry promotes the success of the tourism industry, not only in Europe and the United States, Asian countries have a very bright performance in the development of film and television tourism in the past decade, which is most obvious in South Korea. Since the end of 1990, South Korea has paid attention to the development of Korean pop culture, with cultural products such as drama films and music as the main output. Until now, Korea's film and television tourism has been the most successful case in Asia.

From the Cross-Strait Economic Cooperation Framework Agreement (ECFA) signed in 2010, the opening of Taiwanese Chinese-language films was released and screened without restrictions on import quotas after being reviewed and approved by the competent authorities. The expansion of Taiwan's film and television industry has also attracted many Taiwanese film and television stars to compete for the filming of the motherland.

\section{B. Degree of involvement}

The concept of Involvement was first proposed by Sherif and Cantril (1947), which means that people's personal views on something are different, depending on how high or low they are in Ego involvement. When an individual is involved in something, the lower the degree of acceptance of the opposite opinion, the higher the degree of acceptance of the same opinion (Lin Shijie 2009 Luo Wenkun, Zhong Yizhen, Luo Yanhong 2015). In short, it is the individual's perception of the importance or interest associated with any stimulus or situational feeling (Antil, 1984; You Zhiqing, Wang Junjun, 2013; Zhang Xinfang, 2014).

At present, the concepts involved in relevant research have been widely used in advertising (Krugman, 1965), tourism and leisure (Celsi \& Olson) and consumption (Laurentand \& Kapferer, 1985) and other research fields. According to the research in different fields, the definition of involvement is also different. Table 1 is the definition of involvement of various scholars. The study defines the involvement as the degree to which an individual perceives something because of his or her 
own needs, interests, and importance.

Table 1. Definition of degree of involvement

\begin{tabular}{lll}
\hline Scholar & Age & Definition \\
\hline Sherif \&Cantril 1947 & $\begin{array}{l}\text { The extent to which an } \\
\text { individual feels relevant to } \\
\text { himself in any stimulus or } \\
\text { situation } \\
\text { In a particular situation, certain } \\
\text { stimuli cause personal feelings } \\
\text { of importance and interest } \\
\text { Antil } 1983\end{array}$ \\
Zaichkowsky 1985 & $\begin{array}{l}\text { Individuals are based on internal } \\
\text { needs, the degree to which } \\
\text { values and interests are } \\
\text { conscious of the target } \\
\text { Involvement is based on this } \\
\text { value, goal and self-concept, } \\
\text { reflecting the level of personal } \\
\text { decision-making } \\
\text { Involvement refers to the level } \\
\text { of consumer price, importance } \\
\text { and self-relevance }\end{array}$ \\
Luo Wenkun, 2015 \\
$\begin{array}{l}\text { Zhong Yiwei, } \\
\text { Luo Yanhong }\end{array}$
\end{tabular}

Houston and Rothschild (1978) and Bloch \& Richins (1983) counted several characteristics and found that regardless of the type of involvement, it consisted of three factors: individual, product and situation. According to the scholar's influence factor on the degree of involvement.

\section{Personal}

When consumers are interested in a certain product, depending on the needs, importance, interest or values of the consumer, the consumer will be noticed, and even the same product will be different for different consumers. Involved behavior.

\section{Product}

When a product brings consumers a higher risk of purchase and use, the degree of consumer involvement in the product will increase. The so-called risks refer to entity risks, psychological risks, performance risks and financial risks.

\section{Situation}

Finding the same product may cause consumers to have different levels of involvement because of different contexts. The situational factor is the biggest source of influence for context involvement. But the impact on persistent involvement is small.

Different levels of consumer involvement can be divided into high-involvement and low-involvement according to the purchasing decision process. High-involved ethnic groups pay a high degree of attention to purchasing decisions, and consumption patterns tend to be rational decision-making models. The product will be collected first, analyzed and compared.

\section{Correlation between film and television and the degree of involvement \\ The emotional and behavioral involvement of the audience is}

the main motivation. It can be observed that the psychological motivation positively affects the audience to go to the shooting location for film and television sightseeing. The research results show that the more emotional involvement the audience puts in watching movies or TV dramas, they are doing The possibility of film and television sightseeing is greater.

\section{Glamour engineering}

"Charm" is a vague concept that has historically been difficult to make a specific evaluation. Charisma can be seen as a general term for conscience, attraction, inducement, appeal, and motivation. The expression of personal character and behavior is the agitation and communication of interpersonal interaction emotions. It is a kind of mental state with power, prestige and admiration. It is also a comprehensive expression of multi-faceted ability. "Charm" comes from inner self-image. (self-image), and self-image determines the intensity and depth of glamour (Zhuang Xianzhi, Li Xueran, Chen Yizhen, Ma Minyuan, 2009). Liu Weigong (2005) mentioned that cultural value-added can attract consumers. Good products are attractive products. As the value of film and television texts attracts consumers, "glamour" is the driving force that drives people to watch movies and convey their ideas. Force, so in order to understand the fascinating nature of film and television, the film as a special form of goods, understanding the needs of the audience has become an important factor in the development of film and television.

The method of judging glamour was initiated by the Japanese scholar Masato Ujigawa in 1991 to bring together a number of scholars to launch "Preference-Based Design" with the aim of "creating attractive products, technology and knowledge of space". It is the interface between designers and consumers, and the theoretical basis of fascinating engineering is divided into the following three points: basic theory theory, modeling research and analysis technology, and design (Editor's Department of Charisma Engineering, 1992)

\section{A. Evaluation of construction method definition}

The evaluation of the structure method to extract the "glamour factor" is one of the important research methods of the charm engineering, and the evaluation structure method proposes a theoretical basis for the analysis of the product charm factors. A method proposed by the Japanese scholar Sanui (Masato, 1997) to help to better understand the subject's psychological cognitive level of a certain thing, in the form of in-depth interviews, let the subjects compare preferences. Most related researches choose to use the evaluation method to extract the charm factor when judging the charm factor. This method can be applied not only in product design, manufacturing in the field of red studies, but also in cultural and creative industries, such as animation, fashion design, and sightseeing. Because this study is to learn about the respondents' perceptions of (Living with medicine and mercy) micro-movies, the selection of products is not in pairs, and the purpose of research is not to compare the views between products, so the method of evaluating construction methods is adopted. Judging the charm factor.

\section{B. Implementation Procedures}

The evaluation construction method is mainly used to deeply 


\section{Recent Developments on Information and Communication Technology (ICT) Engineering-Meen, Yang E Zhao ISBN: 978-981-14-2136-5}

understand the perception of a subject in a subject's mind. In the in-depth interview method, the subject is asked to discuss the micro-movie, and then the list of personal cognition concepts obtained is sorted out, and finally the individual traits of the target object are summarized. Evaluation Grid Method (EGM) operation flow, the implementation steps are as follows:

1. Preparation before the interview: Recording or video recording equipment used for interviews.

2. Conduct interviews.

3. Please be tested at any time to take pictures in the film.

4. The film clips that will be taken are grouped according to the preferences of the subjects, and the more groups, the better.

5. Ask the subject to explain the reasons for grouping (there are differences or reasons for preference) in the order of grouping, and establish the original evaluation item.

6. According to the original evaluation project, further inquire about the lower (specific image) and superior (abstract concept).

7. Draw an EGM diagram.

\section{Charm Factors Related Research}

Charm engineering is mainly to explore how to master the "sensibility" of human psychological process. The initial development of glamour engineering is after industrialization. At the beginning of the application, most of the industrial products are discussed. At present, fascinating engineering is used in tourism, leisure and film research. Explain separately:

Chen Junzhi and Chen Yizhen (2013) used the EMG evaluation construction method of fascinating engineering to explore the connotation of consumer visual interpretation image in movie posters. It is found that to reach the movie poster that attracts consumers' vision, it must be able to use pictures to tell stories. From the design and the shop must be mixed with local cultural characteristics, the background of the characters inside will give people a deep sense of identity, seeing can make people feel moved

Chen Wendong (2009) explored the research on the charm factor of bamboo art industry in Zhushan Town, Nantou County, and found that the subjects were concerned with "local impression", "history and development of bamboo products", "development and application of bamboo art industry", "sightseeing planning" All four have a good response, in which the specific glamour factor is based on the practical value of bamboo products, and the abstract glamour factor is affirmed by Stuart nostalgia. In addition, the inductive industry is currently facing the transition of craftsmanship, and the product styling and research and development are insufficient. Insufficient promotion of bamboo culture, imperfect product channel construction, and development of the current status of local bamboo art brand identification planning industry. From the above research, it can be found that the current attractive engineering application in film and television posters and local industries can explore the most attractive elements of nostalgia and theme or experience. This study hopes to use this research method to explore the attractive factors of the respondents' (Living with medicine and mercy) micro-movies.

\section{Results}

This study conducts in-depth interviews with teachers, audiences and creators of micro-film related courses through the fascinating engineering evaluation structure method. Finally, the respondents' data are collected and extracted to extract the original reason and specific items. And "abstract reasons." Integrate the charm factor evaluation structure diagram of the following figure 1 .

From the above picture, we can understand that the original reason is to attract the viewer's main charm factor. It can be obtained by interviewing several high-investigators. The main mainstay of this micro-movie is that the "traditional culture inherits" and discusses "Chinese and Western medicine". "The issue", the "Operational Techniques" of the whole film attracted the audience to step into the plot with the director's footsteps. A "documentary" with "humanistic care", the "transfer concept" is unavoidable. "-"Golden Medical Ethics", the concept attracts audiences through "Touching Real Story", "Movie Script Design" and "Film Lens Design". In particular, "Emotional Aesthetics Communication", "Touching Real Story", "Gunning Mirror" and "Golden Medical Ethics" received the most attention.

\section{Conclusion}

In order to discover the charm factors of microfilms which can attract the audiences, the microfilm creation "Living with Medicine and Mercy " had been taken as an example to explore the charm factors to drive people to watch this microfilm. This research used the Evaluation Grid Method theory from Preference-Based Design, and interviewed six highly involved people in microfilm to proceed related research. The attractiveness factors consisted of originality factors, abstract attractiveness factors and concrete attractiveness factors. Among them, the microfilm real and touching story, camera movements, and the emotional aesthetic communication are most recognized by the interviewees. The attractiveness factors can provide effective references for a microfilm creation.

\section{References}

[1] Bowler, I. R., \& Warburton, P. R., (1986). An Experiment in the Analysis of Cognitive Images of the Environment: The Case of Water Resources for Recreation in Leicestershire. Leicester University Geography Department.

[2] Downs, R. M., (1976). Personal constructions of personal construct theory, In Moore, G.T., and Golledge, R. G., (Eds). Environmental Knowing: Theories, Research, andMethods. Stroudsburg, Pennsylvania, 41: 315-319, Academic Press.

[3] Kelly, G. A., (1955). The psychology of personal constructs. 2 volumes, New York: Noton.

[4] Ryan, C., (1991). Recreational Tourism: A Social Science Perspective. London: Routledge.

[5] Ujigawa, M., (1999). Miryoku Engineering, Miryoku Engineering Forum, Kaibundo (Japanese) 1982] 
Recent Developments on Information and

Communication Technology (ICT) Engineering-Meen, Yang \& Zhao

ISBN: 978-981-14-2136-5

\begin{tabular}{|c|}
\hline Specific matters \\
\hline Cose-up lens, large aperture and shallow focus to catching eyes \\
\hline Religious elements (incense burners, etc.) \\
\hline Express your heart with the side of the item \\
\hline Daily life details \\
\hline Close-up large aperture focal convergence \\
\hline The color of the picture is dark and powdery \\
\hline Occasionally embellished with Huang Mingguang \\
\hline Composition view tilt \\
\hline Looking up at the lens to create a sense of beauty \\
\hline Looking up at the lens to create a devout vision \\
\hline Big close-up character \\
\hline Upgrade slow motion \\
\hline Rustic and elegant herbs \\
\hline Medical treatment close-up \\
\hline Vlewing the unique architecture of Minnan (Tulou) \\
\hline Minnan Traditional Medicine \\
\hline Real image record interview \\
\hline Ambience \\
\hline Character emotion mining \\
\hline Rich collection of materials \\
\hline Old Chinese Doctor \\
\hline Use light and fog effects to create a medical temperament \\
\hline Scene occlusion and specular reflection create a virtual relationship \\
\hline Observation video \\
\hline Picture language, sound language, sound and picture combination \\
\hline
\end{tabular}
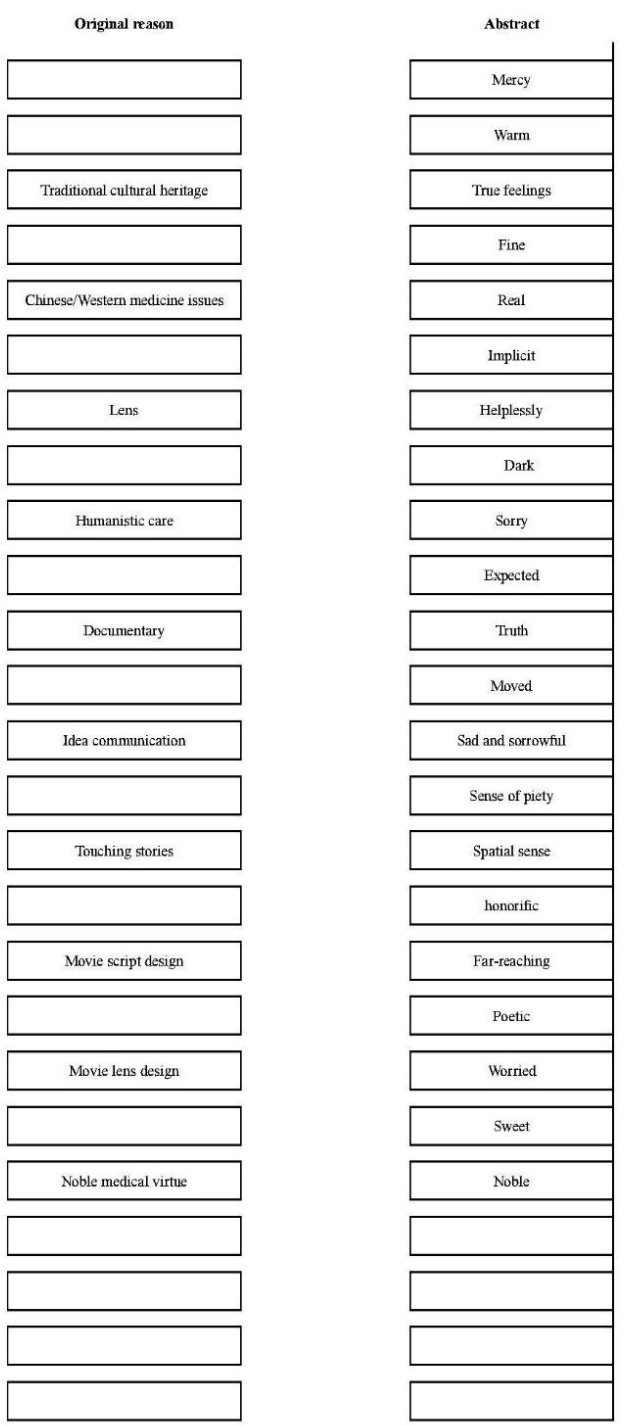

Figure 1. The charm factor evaluation structure diagram of the microfilm 